\title{
VASCULAR REFLEX RESPONSES INDUCED BY AN INTRAARTERIAL INJECTION OF AZAAZEPINO- PHENOTHIAZINE, ANDROMEDOTOXIN, VERATRIDINE, BRADYKININ AND KALLIKREIN AND BLOCKING ACTION OF SODIUM SALICYLATE
}

\author{
Koroku Hashimoto, Seiji Kumakura \\ AND Norio TAIRA* \\ Department of Pharmacology, Tohoku University School of Medicine, \\ Sendai, Japan
}

Since R. Hunt (1898) had observed effects of electrical stimulation of the cut central end of the sciatic nerve on the systemic blood pressure obtaining the depressor or pressor reflex by the variable strength of stimulation under ether anesthesia, Howell and Austin (1899), RAnson and Billingsley (1916), Gordon (1943), MARIN, Corriol and ZWIRn (1953), MCLENNAN (1961), YoKota and FUJIMORI (1963) and others discussed on whether different kinds of afferent fibers or modified activities of the vasomotor center under anesthesia would be responsible to the different mode of the reflex response in the systemic blood pressure. The general excitation of sympathetic nerve as the due cause of pressor reflex was considered beyond dispute. Later TRUETA et al. (1947) applied a tourniquet to the root of thigh of rabbit on one side and observed the constriction of the femoral and renal arteries but the dilatation of the mesenteric artery. The reflex vasoconstriction and dilatation are assumedly obtained by stimulation of afferent fibers in the sciatic nerve due to the mechanical pressure or the resulted anoxia by application of tourniquet. Recently CHAPMAN and WOLFF (1958) observed the induction of pain sensation by an intradermal injection of bradykinin solution and GUZMAN et al. (1962) obtained the reflex change of systemic blood pressure and vocalization with the respiratory excitation by an intraarterial injection of $1-2 \mu \mathrm{g}$ of bradykinin and larger amount of serotonin, histamine, acetylcholine and $\mathrm{KCl}$, which they described as the pseudo-affective reflex responses of WOODWORTH and SHERRINGTON (1904). Meanwhile SETo and his colleague (1963) could not find any

Received for publication April 1, 1964

* 橋本虎六, 熊倉清次, 平 則夫 
morphological characteristics for pain sensation in the afferent nerve terminals in different kinds of organs. Authors were wholly unprepared for the definite and constant occurrence of pressor reflex induced by an intraarterial injection of newly synthesized azaazepinophenothiazine derivatives into the femoral artery of hindlimb preparation of dog with intact sciatic and femoral nerves. In further progress of study, some other drugs were found to be also effective for induction of such kind of reflex. In this paper authors describe these observations and the pharmacological analysis of the mechanism of reflex induced by intraarterial administration of these chemical agents.

\section{METHODS}

The hindlimb cross-circulation and the combination of cross-circulations of the hindlimb and the kidney were prepared on dogs. Recepient mongrel dogs were anesthesized with $30 \mathrm{mg}$ per $\mathrm{kg}$ of sodium pentobarbital given intravenously and those for donor dogs with $1 \mathrm{~g}$ per $\mathrm{kg}$ of urethan, and $10 \mathrm{mg}$ per $\mathrm{kg}$ of morphine subcutaneously. Fifty mg of whale heparin (HAshimoto et al., 1963) which is twice more potent in anticoagulant activity than beef heparin was initially given to the donor dog and successively $10 \mathrm{mg}$ at one hour intervals.

1) The hindlimb cross-circulation (Fig. 1, a)

The left hindlimb of one $\operatorname{dog} \mathrm{A}$, male and around $10 \mathrm{~kg}$, was divided from the body, of which the sciatic and femoral nerves remained intact. The divided limb was perfused through the femoral artery with the blood of a donor dog B, male and over $15 \mathrm{~kg}$. A Sigmamotor pump was set between the carotid artery of the dog B and the perfused femoral artery of the divided hindlimb for maintaining the constant volume of perfusion. The perfusion pressure was adjusted similar to the level of carotid blood pressure of the $\operatorname{dog} \mathrm{A}$. The blood pressure of the carotid artery and the respiratory movement of $\operatorname{dog} \mathrm{A}$ and the perfusion pressure were registered on the smoked drum. 24 experiments were done.

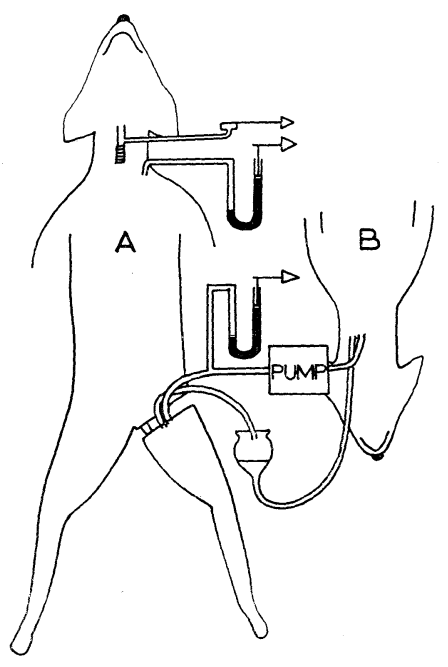

FIG. 1, a. A, hindlimb preparation; B, donor dog. 
2) The combination of cross circulations of the hindlimb and the kidney (FIG. 1, b) The kidneys were isolated first and the left himblimb was isolated successively. The abdominal aorta and caval vein were approached retroperitoneally through a widely retracted incision of the right side of abdomen. Three or more pairs of lumbal arteries and small arterial branches were ligatured and cut for convenience to

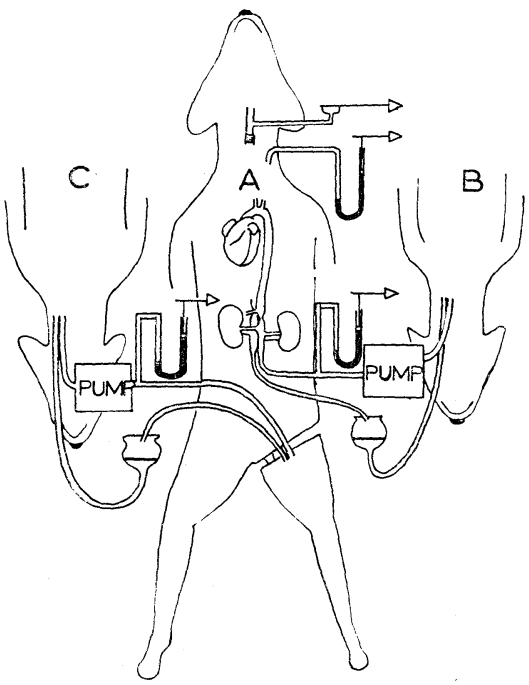

FIG. 1, b. A, kidney and hindlimb preparations; B, donor dog for kidney preparation; C, donor dog for hindlimb preparation.

perfuse both kidneys through aorta. After $10 \mathrm{mg}$ of whale heparin was given to the receipient $\operatorname{dog} A$, a polyethylen tube of which outer diameter was $6 \mathrm{~mm}$ was cannulated centripetally into the abdominal aorta setting the tip of cannula around $1 \mathrm{~cm}$ apart from the aperture of the left renal artery. Another cannula was inserted into the caval vein in parallel with the aortic cannula. A Dale-Schuster pump was set between the carotid artery of donor $\operatorname{dog} B$ and the aortic cannula of $\operatorname{dog} A$. As soon as the blood perfusion started through the aorta to the kidneys, the aorta was clamped between the levels of roots of the mesenteric and right renal arteries, and then clamping of the caval vein between roots of the hepatic and renal vein was followed so as to drain the total renal outflow to the venous reservoir by $20 \mathrm{~cm}$ drop of hydrostatic pressure, which was connected to the jugular vein of the donor dog. The perfusion pressure was adjusted to the systemic blood pressure measured at the carotid artery by regulating the pumping volume. The divided hindlimb was perfused successively with the blood of donor $\operatorname{dog} \mathrm{C}$, of which perfusion system was the same as described above. When the preparation was finished, 10 to $30 \mu \mathrm{g}$ of epinephrine or the same dose of acetylcholine was injected into the jugular vein for observing the reflex dilatation or reflex constriction in the renal artery (FIG. 4, $g$ and $h$ ). When the definite reflex response was not obtained, an incomplete isolation of the kidney was expected, because there were so many abnormalities of small arteries around roots of the renal artery which could not find during preparation. Such one was discarded. Five preparations were successfully arranged.

Dimethylaminopropyl-tetrahydro-azaazepinophenothiazine (RPP 201), other azaazepinophenothiazine derivatives and andromedotoxin were prepared by Research Laboratories of Sankyo Company (FIG. 2). Veratridine was kindly given by profes- 

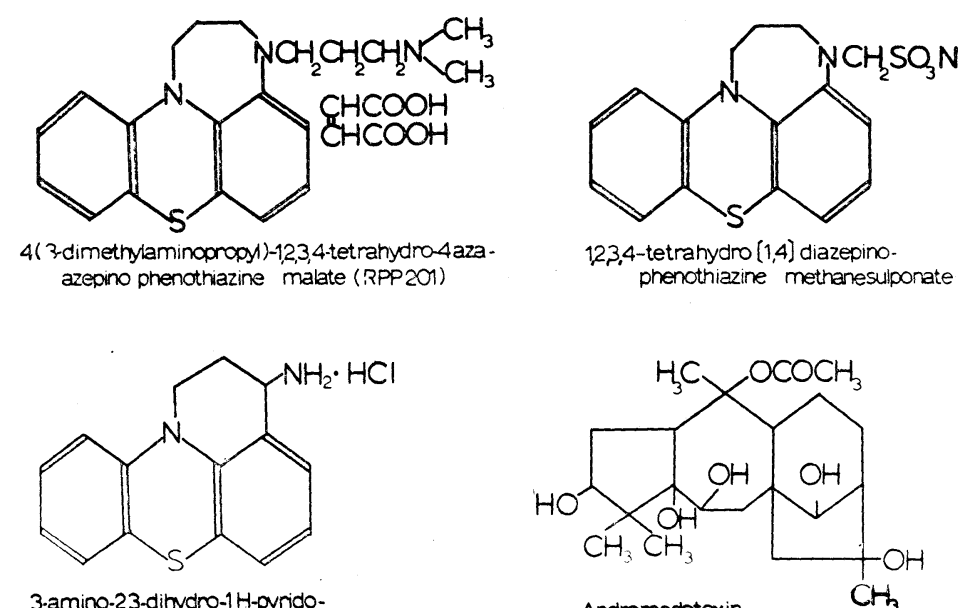

phenothiazine hydrochloride

FIG. 2. Structural formula of azaazepinophenothiazine derivatives and andromedotoxin.

sor Otto Krayer, Harvard Medical School. Bradykinin synthesized by Dr. M. BodanSKY, Squibb Institute for Medical Research and synthetic preparation (sandoz) kindly given by Professor McKeen CATtell were used. BOL-148 was kindly given by Sandoz Yakuhin Company. Drug solution prepared freshly with Ringer's solution before use and $0.1 \mathrm{ml}$ was injected into the femoral artery over a 10 seconds period.

\section{RESULTS}

1) RPP 201 constricted the femoral artery but no reflex response either in the respiration or in the systemic blood pressure was observed in a smaller dose $(10 \mu \mathrm{g})$. When the dose level increased (50 to $100 \mu \mathrm{g})$, a preceding dilatation appeared and over a certain dose level (200 to $300 \mu \mathrm{g})$ the femoral artery dilated definitely, accompanying the reflex pressor response and the respiratory excitation (FIG. 3. a to e and FIG. 4. c, d, and e). The vocalization was occasionally observed. The reflex response could be elicited repeatedly at 5 to 10 minutes intervals. The reflex pressor response in the systemic blood pressure and the reflex stimulation of respiration could not be abolished either by cutting the femoral nerve, by exstirpating the lumbal and sacral sympathetic ganglia or by use of antiadrenergic (tolazoline), anticholinergic (atropine), antiserotonic (BOL-148), antihistamic (benadryl hydrochloride), neuromuscular blocking (succinylcholine) and ganglion blocking (hexamethonium) agents, while it disappeared by pretreatment with procaine and persistently by cutting the sciatic nerve (FIG. 3. $f$ to $\mathrm{m}$ ). The preceding administration of sodium salicylate into the femoral artery blocked definitely the reflex response in the blood pressure and respiration (FIG. 5. a).

The reflex pressor response was also induced by injection of this com- 


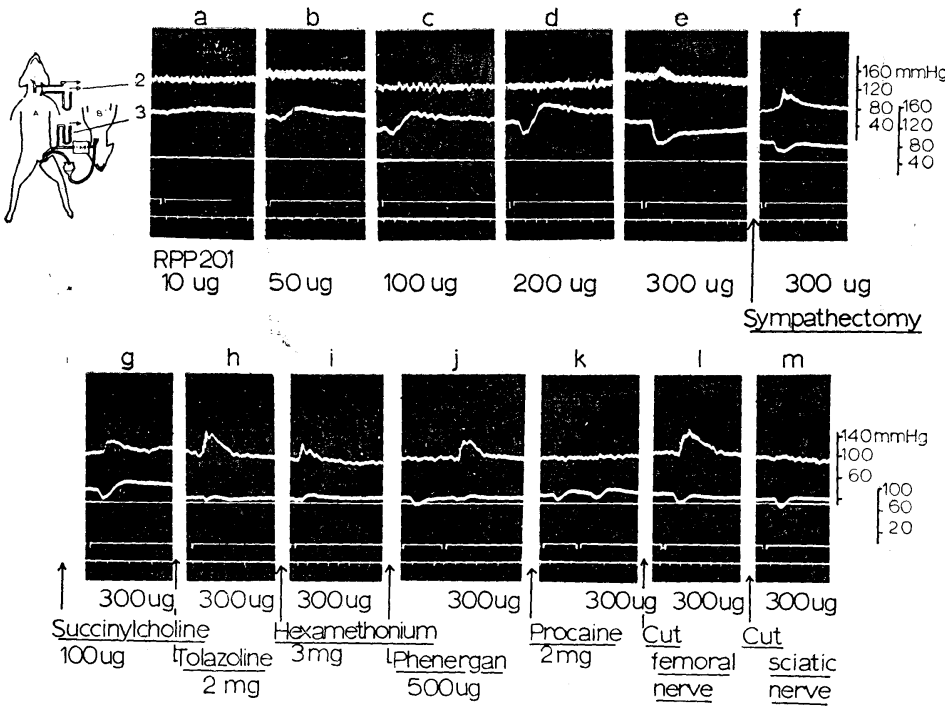

FIG. 3. Reflex response in the blood pressure induced by RPP 201 given into the femoral artery.

Upper curve, systemic blood pressure; lower curve, perfusion pressure for the hindlimb preparation; time marks at 30 seconds intervals.
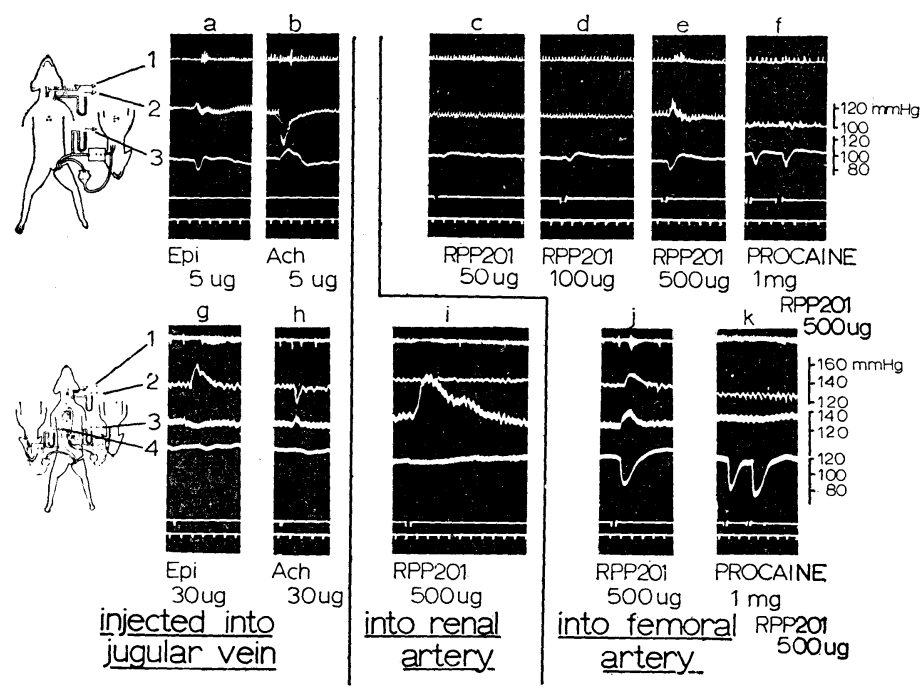

FIG. 4. Reflex response induced by RPP 201 given into the femoral artery in the blood pressure and the respiration.

Upper row: Uppermost curve, respiratory movement; second, systemic blood pressure; third, perfusion pressure of the hindlimb preparation; time marks at 30 seconds intervals. Lower row: Uppermost curve, respiratory movement; second, systemic blood pressure; third, perfusion pressure of the kidney preparation, fourth, perfusion pressure of the hindlimb preparation. 
pound into the brachial artery of forelimb preparation as was observed on the divided hindlimb preparation (FIG. $5, \mathrm{~b}$ and $\mathrm{c}$ ).

The reflex rise of systemic blood pressure disappeared in a spinal dog transsected at the first cervical level.

The reflex response was tested on the combined preparation of crosscirculations of the kidneys and the hindlimb. When RPP 201 was injected into the femoral artery of divided hindlimb, the reflex constriction of the renal arteries and also the pressor reflex of the carotid blood pressure accompanying the respiratory stimulation was observed (FIG. 4. j.).

2) The same pressor reflex with the respiratory excitation was obtained by use of 3 amino-2, 3 dihydro-pyridophenothiazine (300 to $500 \mu \mathrm{g}$ ) but not by use of tetrahydro-diazepinophenothiazine $(200-1000 \mu \mathrm{g})$, chlorpromazine (200$1000 \mu \mathrm{g})$ and phenothiazine $(1-2 \mathrm{mg})$. Vasodilators such as histamine $(1-100 \mu \mathrm{g})$, acetylcholine $(1-100 \mu \mathrm{g})$, papaverine $(100 \mu \mathrm{g})$, ATP and ADP $(1-100 \mu \mathrm{g})$, aminophylline $(100-200 \mu \mathrm{g})$, nitroglycerine $(600 \mu \mathrm{g})$, isoproterenol $(0.1-1.0 \mu \mathrm{g})$, Apresoline $(2 \mathrm{mg})$ and Persantin $(10 \mu \mathrm{g})$ and vasoconstrictors such as epinephrine ( 1 to $10 \mu \mathrm{g}$ ), ergotamine $(5 \mu \mathrm{g})$ and angiotensine $(1 \mu \mathrm{g})$ had an apparent direct

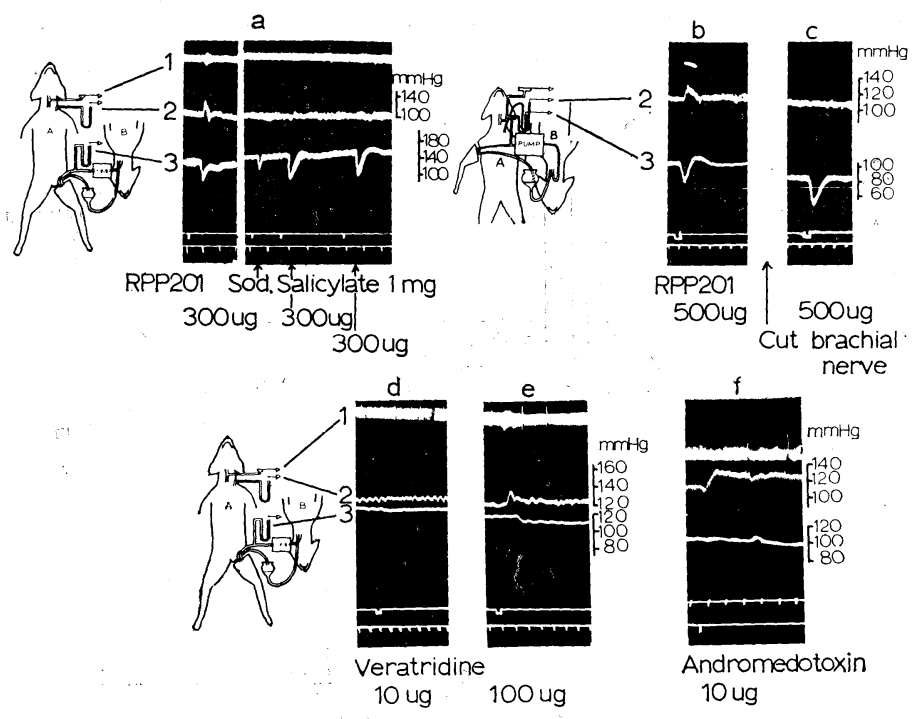

FIG. 5. Reflex responses in the blood pressure and the respiration induced by RPP 201, veratridine and andromedotoxin.

Upper left (a), blocking action of sodium salicylate; upper right (b and c), reflex response induced by RPP 201 given into the brachial artery in the forelimb preparation; lower left (d and e), reflex response induced by veratridine given into the femoral artery; lower right (b), reflex response in the blood pressure and the respiration induced by andromedotoxin. Uppermost curve, respiratory movement; second, systemic blood pressure; third, perfusion pressure of limb preparation; time marks at 30 seconds intervals. 
effect on the femoral artery but did not cause the reflex response both in the systemic blood pressure and in the respiration.

3) Veratridine in a smaller dose of $10 \mu \mathrm{g}$ did not produce any effect both in the peripheral vascular vessel and also in the systemic blood pressure, however $100 \mu \mathrm{g}$ of it induced the definite and long lasting pressor reflex accompanying the respiratory excitation, while the direct dilatory effect on the peripheral artery was observed with a delay of 30 minutes or more (FIG. $5 d$ and e).

4) Andromedotoxin $(10 \mu \mathrm{g})$ induced a long lasting pressor reflex accompanying the respiratory excitation but there was no observable effect or a slight dilatation in the femoral circulation (FIG. 5. f).

5) Bradykinin (1-2 $\mu \mathrm{g})$ induced the similar size of dilatation to that obtained by RPP 201, accompanying the reflex depressor, pressor or mixed response in the systemic blood pressure and the reflex excitation of respiration (FIG, 6. a, to e). $\alpha$-chloralose anesthesia emphasized the respiratory excitation, while pentobarbital made the depressor reflex more prominent (FIG. 6 . $\mathrm{b}$ and $\mathrm{c}$ ). The mixed response, i. e., initial depressor followed by pressor reflex was converted to the pressor one when the skin of leg was removed

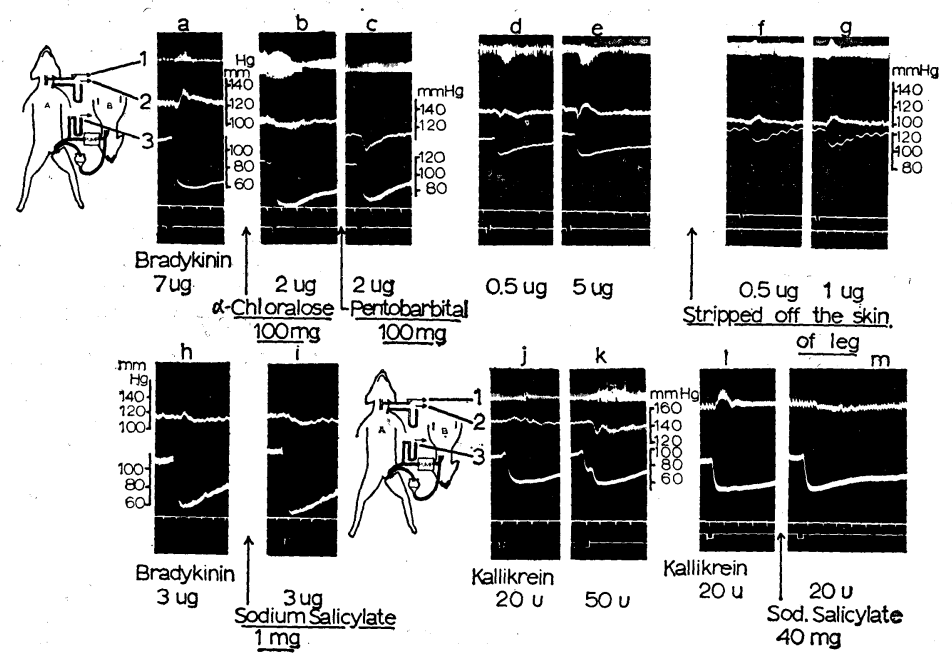

FIG. 6. Reflex responses in the blood pressure and the respiratory movement induced by bradykinin and kallikrein given into the femoral artery.

Upper left ( $a, b$ and c), effect of anesthetic agents; upper right (d to g), effect of stripping off the skin of leg; lower left (h and i), blocking action of sodium salicylate in the pressor reflex induced by bradykinin; lower right ( $\mathrm{j}$ to $\mathrm{m}$ ), blocking action of sodium salicylate in the pressor reflex induced by kallikrein. Uppermost curve, respiratory movement; second, sytemic blood pressure; third, perfusion pressure of hindlimb preparation; time marks at 30 seconds intervals. 
(FIG. 6, f and g). Furthermore a preceding injection of sodium salicylate (1-3 mg) into the femoral artery could convert the pressor reflex to the depressor one (FIG. 6, h and i), while the depressor response was not changed even with the treatment of sodium salicylate. Repeated administrations of bradykinin never produced explicitly the edema of perfused leg, when the perfusion pressure was maintained around $100 \mathrm{~mm} \mathrm{Hg}$.

6) Kallikrein (0.1 to 1 unit) was not effective in the reflex response though the femoral artery dilated apparently. In an increasing dose (over 10 units) the depressor or pressor reflex was observed as induced by bradykinin (FIG. $6, \mathrm{j}$ and $\mathrm{k}$ ). Sodium salicylate blocked the pressor reflex response, while it did not modify the peripheral action of kallikrein (FIG. 6, 1 and $\mathrm{m}$ ).

\section{DISCUSSION}

The depressor and pressor reflexes were observed by electrical stimulation of the cut central end of the sciatic nerve first by HUNT in 1895 and he suggested the existence of two kinds of afferent fibers, one for induction of the depressor reflex and other for that of the pressor reflex. However, there is a doubt concerning the afferent fiber responsible for the depressor reflex, because the depressor reflex is not observed under curare, but there is only under ether or chloroform anesthesia. YokOTA and FUJIMORI concluded that the depressor reflex obtained under anesthesia must be due to the depressed state of vasomotor center.

In this study, RPP 201, veratridine and andromedotoxin caused constantly only a pressor reflex and bradykinin and kallikrein induced a pressor, depressor or mixed reflex response. The pressor reflex which was induced not only by RPP 201, veratridine and andromedotoxin but also by bradykinin and kallikrein was completely blocked by preceding injection of sodium salicylate into the femoral artery. On the contrary, the depressor reflex disappeared after removal of the skin of the leg, which was induced by injection of bradykinin. Even when only the pressor reflex was observed by injection of kallikrein, the depressor reflex took place after pretreatment of sodium salicylate. Furthermore this depressor reflex was observed not only under pentobarbital anesthesia but also under $\alpha$-chloralose anesthesia. Thus authors believe that HUNT made the correct interpretation on these depressor and pressor reflexes and that the depressor reflex is induced by excitation of the sensory nerve fibers from the skin while the pressor one is caused by that from the muscle, joint and other parts than the skin.

The vasomotor reflex, either the depressor or the pressor one accompanies the respiratory excitation. The respiratory excitation observed by RPP 201 is completely blocked by preceding injection of sodium salicylate into the femoral artery (FIG. 5, a). These reflexes are exactly induced by the excita- 
tion of sensory nerves, probably subserving the pain sensation. The analgesic action of salicylates was poorly understood in the past. Recently GUZMAN et al. observed the inhibitory action of acetylsalicylate injected intravenously against nociceptive or pseudoaffective reflex induced by the intraarterial administration of a small amount of bradykinin, but ColLIER and LiM could not block such reflex when bradykinin was given intracutaneously. CoLLIER and his collaborators (1963) found the blocking action of acetylsalicylates given intravenously against the bronchial spasm induced by bradykinin. Authors conclude from the reference to these experimental results that the analgesic action of salicylates is peripheral and the pain sensation from the muscle, tendon, joint or periosteum is blocked by these analgesic compounds.

\section{SUMMARY}

The cross circulation technique was applied for perfusing the innervated hindlimb and kidney preparation for analysing the reflex response in the systemic blood pressure and the respiratory movement, when dimethylaminopropyl-tetrahydro-azaazepino-phenothiazine (RPP 201), andromedotoxin, veratridine, bradykinin and kallikrein were injected into the femoral artery of hindlimb preparation.

The pressor reflex response was constantly observed by use of RPP 201, andromedotoxin and veratridine but the depressor, or the pressor or the combined reflex was obtained by use of bradykinin and kallikrein. The depressor reflex induced by bradykinin disappeared when the skin of leg was removed, while the pressor reflex was reversed to the depressor one by preceding injection of sodium salicylate into the femoral artery. The pressor reflex with respiratory excitation induced by RPP 201 was also blocked by sodium salicylate. The afferent fibers in the sciatic nerve were principally responsible to the reflex, and anticholinergic, antiadrenergic, antihistamic, antiserotonic, neuromusclar blocking and ganglion blocking agents did not block the reflex but procaine did it. Authors conclude that the depressor reflex response is probably induced by the excitation of afferent fiber from the skin while the pressor one is originated from the muscle, joint and other parts than the skin, and that sodium salicylate blocks peripherally these nociceptive or pseudoaffective reflex responses, especially originated from the muscle and joint but not from the skin.

This experiment was performed with a great help from Pharmacological Research Foundation (Japan) and Squibb Institute for Medical Research (U.S.A). Authors express many thanks to Professor O. KRAYER, Harvard Medical School, Professor McKeen Cattel, Cornell University Medical College, Dr. M. Bodansky, Squibb Institute for Medical Research and Dr. G. SunAGAwA, Research Institute of Sankyo Company for giving us these precious compounds. 


\section{REFERENCES}

1) Hunt, R., J. Physiol., 18: 381 (1895).

2) Howell, W.H. and Austin, N.F., Amer. J. Physiol., $3: 22$ (1899).

3) Ranson, S. W. and Billingsley, P. R., Amer. J. Physiol., $42: 16$ (1916).

4) Gordon, G., J. Physiol., $102: 95$ (1943).

5) Morin, G., Carriol, J. And Zwirn, P., J. Physiol. (Paris) 45: 202 (1953).

6) Yokota, T. And Fujimori, B., Tohoku J. Exp. Med., 78: 381 (1963).

7) Trueta, J. et al., Studies of the Renal Circulation, Blackwell Science Publications Oxford (1947).

8) Chapman, L.F. and Wolff, H. G., Science 128: 1208 (1958).

9) Guzman, F., Braun, C. And Lim, R. K.S., Arch. int. Pharmacodyn., 136: 353 (1962).

10) Woodworth, R.S. And Sherrington, C.S., J. Physiol., $31: 234$ (1904).

11) Seto, H., Studies on the sensory innervation, 2nd edition, Igaku Shoin, Tokyo, 1963.

12) Hashimoto, K., Matsuno, M., Yoshizawa, Z. and Shibata, T., Tohoku J. Exp. Med., $81: 93$ (1963).

13) Collier, H.O. J. ANd Lee, I. R., Brit. J. Pharmacol., 21 : 155 (1963).

14) Collier, H.O.J., Proceedings of the First International Pharmacological Meeting, 9: 47 (1963).

15) McLennan, H., Pflügers Arch., $273: 604$ (1961). 